\title{
A Convenient Method for Conversion of Acetylenic Derivatives into Conjugated Dienes via $\alpha$-Allenic Alcohols*
}

\author{
ALF CLAESSON \\ Department of Organic Pharmaceutical Chemistry, Biomedical Center, University of Uppsala, \\ Box 574, S-751 23 Uppsala, Sweden
}

\begin{abstract}
4-Alkoxy- and 4-(tetrahydro-2-pyranyloxy)-2butyn-1-ols are in most cases quantitatively converted into conjugated dienes when treated with lithium aluminium hydride in refluxing THF or similar solvents. The reactions proceed via $\alpha$-allenic alcohols. The dienes are free from positional isomers and the formation of alkenynes, which occurs in some cases, can be completely suppressed by a combination of lithium aluminium hydride and aluminium chloride. Most of the conjugated dienes seem to be formed with low stereoselectivity. The $E, E$ form is the predominant isomer of 2,4-hexadiene while of 4,6-decadiene the $E, Z$ isomer predominates. These latter results may indicate that the attack by hydride on the central carbon atom of the propadienyl group is sterically hindered when the double bond remaining in the same position is formed with $E$ configuration.
\end{abstract}

A few years ago we reported that the acetylenic tetrahydro-2-pyranyloxy (Thp-oxy) compounds 1 and 2 (Table 1) are quantitatively converted into the conjugated dienes 15 and 16 upon treatment with lithium aluminium hydride (LAH) in refluxing tetrahydrofuran (THF). ${ }^{1}$ The reactions proceed via $\alpha$-allenic alcohols (strictly alcoholates), which themselves can be prepared according to the scheme in Table $1 .^{2,3}$

As part of a current project covering different aspects of the chemistry of allenes and acetylenes $1,3,10,24,30$ we are trying to develop new synthetic methods for other functional groups in which these types of compounds are essential. Consequently, it was of interest to evaluate this

* Allenes and Acetylenes X. Part IX: Claesson, A., Olsson, L.-I., Sullivan, G. R. and Mosher, H. S. J. Amer. Chem. Soc. 97 (1975) 2919. apparently simple route to certain conjugated dienes and also to make some mechanistic studies. These continued studies have revealed that (i) most primary and secondary $\alpha$-allenic alcohols are also quantitatively converted into conjugated dienes when treated with LAH in refluxing THF and hence these dienes are directly accessible from the corresponding acetylenes $A$ in Table 1, (ii) the formation of alkenynes which occurs in some cases ${ }^{1}$ can be completely suppressed by a combination of $\mathrm{LAH}$ and aluminium chloride in the step $B \rightarrow C$, (iii) the attack by hydride on the central carbon atom of the allenic group seems to be sensitive to steric hindrance, giving dienes of different stereochemical forms.

The conversion of $\alpha$-allenic alcohols into con. jugated dienes upon treatment with LAH has been reported by other authors, ${ }^{4-6,33}$ most of them starting with substituted 2-butyn-1,4-diols.4,5 Already in 1954 Whiting and Nayler reported that cosmene (2,6-dimethyl-1,3,5,7-octatetraene) could be easily obtained by $\mathrm{LAH}$ reduction of the acetylenic diol 26, a reaction they presumed to proceed via an $\alpha$-allenic alcohol.4 To our knowledge three other substituted 2butyn-1,4-diols have been reported to undergo the same reaction with LAH. ${ }^{5}$ Furthermore, skilful carotenoid chemists have reduced the carotenoids, fucoxanthin and neoxanthin, both of which are $\alpha$-allenic $t$-alcohols, to conjugated

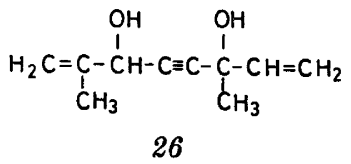

26 
Table 1. Reactions of acetylenes $A$ with lithium aluminium hydride to the conjugated dienes $C$.

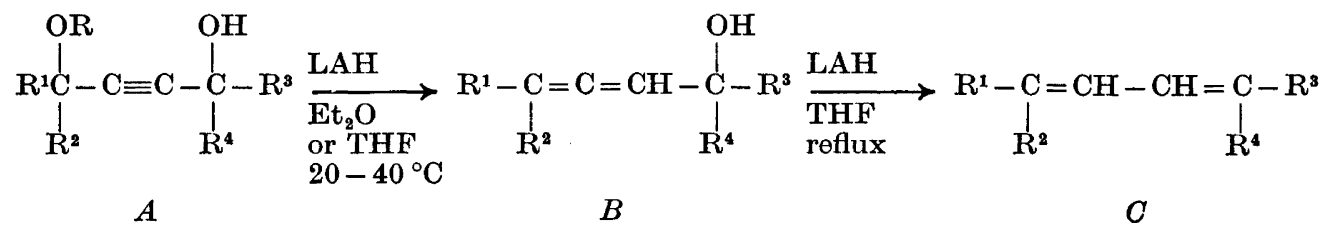

\begin{tabular}{|c|c|c|c|c|c|c|}
\hline $\begin{array}{l}\text { Acety- } \\
\text { lenes } \\
(A)\end{array}$ & $\mathbf{R}$ & $\mathrm{R}^{\mathbf{1}}$ & $\mathbf{R}^{2}$ & $\mathbf{R}^{3}$ & $\mathbf{R}^{4}$ & Dienes $(C)$ \\
\hline $1^{1}$ & Thp & $\mathrm{H}$ & $\mathbf{H}$ & \multicolumn{2}{|c|}{$-\left(\mathrm{CH}_{2}\right)_{5}-$} & $\mathrm{H}_{2} \mathrm{C}=\mathrm{CH}-\mathrm{CH}=\square$ \\
\hline $2^{1}$ & Thp & $\mathrm{CH}_{3}$ & $\mathrm{CH}_{3}$ & $\mathrm{C}_{2} \mathrm{H}_{5}$ & $\mathrm{C}_{2} \mathrm{H}_{5}$ & $\begin{array}{l}15 \\
\left(\mathrm{CH}_{3}\right)_{2} \mathrm{C}=\mathrm{CH}-\mathrm{CH}=\mathrm{C}\left(\mathrm{C}_{2} \mathrm{H}_{5}\right)_{2}\end{array}$ \\
\hline $3^{29}$ & Thp & $\mathbf{H}$ & $\mathbf{H}$ & $\mathrm{C}_{4} \mathrm{H}_{0}$ & $\mathbf{H}$ & 1,3 -Octadiene \\
\hline $4^{2}$ & Thp & $\mathrm{C}_{8} \mathrm{H}_{2}$ & $\mathbf{H}$ & $\mathrm{H}$ & $\mathbf{H}$ & ${ }_{18}^{1,3-H e p t a d i e n e}$ \\
\hline $5^{24}$ & $t-\mathrm{C}_{\mathbf{4}} \mathrm{H}_{9}$ & $\mathrm{C}_{3} \mathrm{H}_{7}$ & $\mathbf{H}$ & $\mathbf{H}$ & $\mathbf{H}$ & $1,3-$ Heptadiene \\
\hline 6 & $\mathrm{CH}_{3}$ & $\mathrm{C}_{5} \mathrm{H}_{11}$ & $\mathbf{H}$ & $\mathrm{H}$ & $\mathbf{H}$ & $\begin{array}{l}\text { 1,3-Nonadien } \Theta \\
19^{15,28}\end{array}$ \\
\hline 7 & Thp & $\mathrm{CH}_{3}$ & $\mathbf{H}$ & $\mathrm{CH}_{3}$ & $\mathbf{H}$ & $\begin{array}{l}\text { 2,4-Hexadiene } \\
20\end{array}$ \\
\hline $7 \cdot d_{3}$ & Thp & $\mathrm{CH}_{3}$ & $\mathbf{H}$ & $\mathrm{CD}_{3}$ & $\mathbf{H}$ & $\begin{array}{l}\text { 1,1,1-Trideuterio-2,4- } \\
\text { hexadiene } \\
20-d_{3}\end{array}$ \\
\hline 8 & $t-\mathrm{C}_{\mathbf{4}} \mathrm{H}_{0}$ & $\mathrm{C}_{3} \mathrm{H}_{7}$ & $\mathbf{H}$ & $\mathrm{C}_{3} \mathrm{H}_{7}$ & $\mathbf{H}$ & $\begin{array}{l}4,6-\text { Decadiene } \\
21\end{array}$ \\
\hline $9^{24}$ & Thp & $\mathbf{H}$ & $\mathrm{H}$ & $\mathrm{C}_{8} \mathrm{H}_{7}$ & $\mathrm{CH}_{3}$ & $\begin{array}{l}\text { 4-Methyl-1,3,-heptadiene } \\
22^{27}\end{array}$ \\
\hline 10 & $\mathrm{CH}_{3}$ & $\mathrm{C}_{3} \mathrm{H}_{7}$ & $\mathbf{H}$ & $\mathrm{H}$ & $\mathbf{H}$ & $\begin{array}{l}\text { 4-Methyl-1,3-heptadiene } \\
22^{27}\end{array}$ \\
\hline 11 & Thp & $\mathrm{C}_{3} \mathrm{H}_{7}$ & $\mathbf{H}$ & $\mathrm{CH}_{3}$ & $\mathrm{CH}_{3}$ & $\begin{array}{l}2 \text {-Methyl-2,4-octadiene } \\
23^{14}\end{array}$ \\
\hline 12 & Thp & $\mathrm{CH}_{3}$ & $\mathrm{CH}_{3}$ & $\mathrm{C}_{3} \mathrm{H}_{7}$ & $\mathbf{H}$ & $\begin{array}{l}2 \text {-Methyl-2,4-octadiene } \\
23^{14}\end{array}$ \\
\hline $13^{3}$ & $\mathrm{CH}_{3}$ & $\left(\mathrm{CH}_{3} \mathrm{O}\right)_{2} \mathrm{CH}-\mathrm{CH}_{2}$ & $\mathrm{CH}_{3}$ & $\mathbf{H}$ & $\mathbf{H}$ & $\begin{array}{l}\left(\mathrm{CH}_{3} \mathrm{O}\right)_{2} \mathrm{CH}-\mathrm{CH}_{2}-\mathrm{C}=\mathrm{CH}-\mathrm{CH}=\mathrm{CH} \\
24 \\
\mathrm{CH}_{3}\end{array}$ \\
\hline 14 & $\mathrm{CH}_{3}$ & $\mathrm{HCOCH}_{2}$ & $\mathrm{CH}_{3}$ & $\mathrm{H}$ & $\mathbf{H}$ & $\begin{array}{l}\mathrm{HO}-\mathrm{CH}_{2}-\mathrm{CH}_{2}-\underset{\mathrm{CH}_{3}}{\mathrm{C}}=\mathrm{CH}-\mathrm{CH}=\mathrm{CH}_{2} \\
25\end{array}$ \\
\hline
\end{tabular}

polyenes with LAH. ${ }^{6}$ Grignard reagents also attack $\alpha$-allenic alcoholates to give conjugated dienes. ${ }^{7,8}$

Finally, the tendency of $\alpha$-allenic alcohols to be converted into conjugated dienes is also reflected in their smooth rearrangements to halogenated dienes, ${ }^{9}$ dienolacetates, ${ }^{10}$ and $\alpha, \beta$ unsaturated ketones, ${ }^{10}$ which reactions probably proceed via the mesomeric 2,3-butadienyl $\leftrightarrow 1,3$ butadien-2-yl carbonium ion. ${ }^{10,11}$

The formation of conjugated dienes from acetylenic diols ${ }^{4,5}$ has not been fully evaluated as a synthetic method, i.e. no diene having a terminal diene group has been prepared, and in all the starting diols at least one of the hydroxy groups has been tertiary as well as 
activated by allylic or benzylic position. In contrast, the synthetic method presented here is now rather well understood as to limitations of the structure of the starting acetylenes and in part to the stereochemistry of the products. Owing to the facile preparation of the acetylenic derivatives $A,,^{1-8,12}$ many conjugated dienes of the type $C$ are thus easily accessible in three steps from commercial chemicals.

According to our opinion the present synthetic method compares favourably with existing ones ${ }^{13}$ owing to the good yields, the absence of positional isomers, and the rather great variation of substituents $R^{\mathbf{1}}-R^{4}$.

\section{SYNTHETIC PROCEDURES}

The preparations of the starting acetylenes 1-14 follow standard procedures, ${ }^{1-3,12}$ and many of them have been described earlier (Table 1).

These acetylenic derivatives were converted into the corresponding dienes by reaction with an excess of LAH in THF or diglyme. The reactions were usually complete ( $>90 \%$ ) within $4 \mathrm{~h}$ as judged by the disappearance of the $\alpha$-allenic alcohols (GLC). The dienol 25, however, was formed slowly; only $36 \%$ of impure material was isolated after $8 \mathrm{~h}$.

The dienes were isolated by ordinary work-up followed by simple distillation or, often more conveniently, by preparative GLC on SE-30. Volatile dienes could also be distilled directly from the reaction mixture, a procedure used in the isolation of very pure (>99\%, GLC) 1,3heptadiene (18) prepared from 5 in diglyme.

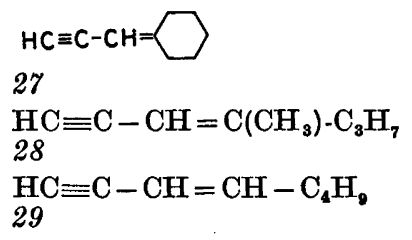

The purity of the distilled dienes is good, better than $90 \%$ in most cases. Furthermore, the dienes are free from positional isomers, and in general further reduction to olefins does not seem to be a problem ( $<3 \%$ ) as long as a great excess of LAH is avoided. In one preparation of the dienacetal $242.5 \mathrm{~mol}$ of LAH were used which, however, led to the formation of 2-3 by-products $(20 \%)$. The isolated by-products had a methyl group at a saturated carbon (NMR), clearly indicating that a reduction of the diene had occurred. The dienol 25 is reduced further even if the normal amount of LAH is used.

As already pointed out in our first paper on this subject alkenynes are sometimes formed as by-products. ${ }^{1}$ This occurs for acetylenic derivatives having $\mathrm{R}^{1}=\mathrm{R}^{2}=\mathrm{H}$ (i.e. 1,3 , and 9 , which give the enynes 27,28 , and 29), or, in other words, when the intermediary $\alpha$-allenic alcohol $B$ has a terminal propadienyl group. The alkenynes are consistently formed in an ap. proximate yield of $10 \%$.

In attempts to suppress the formation of these alkenynes we soon discovered that the combination of LAH with aluminium chloride had a favourable influence in the step $(B) \rightarrow$ diene $(C)$. A molar ratio LAH: $\mathrm{AlCl}_{3}$ of $90-100: 1$ was found to give the diene 15 as a single product ( $>97 \%$ pure, $<0.5 \%$ enyne 27 ) from 1-propadienylcyclohexanol (the intermediate allene in $1 \rightarrow 15$ ). A molar ratio of $50: 1$ of the same reagents in a reduction of 1,2-octadien-4-ol (intermediate in $3 \rightarrow 17$ ) led to 1,3-octadiene, contaminated with $8 \%$ of monoolefins (GLCMS), while a molar ratio of 100:1 gave an almost pure product ( $96 \%$ by GLC, $<0.5 \%$ enyne 29). However, with this modified reagent it is not necessary to isolate the allenic alcohols, because they can be preformed at a lower temperature $\left(\approx 40{ }^{\circ} \mathrm{C}\right)$ using LAH alone. The appropriate amount of aluminium chloride is then added and the mixture is refluxed until the allene is completely converted into the diene.

\section{STEREOCHEMISTRY}

GLC-data on the stereoisomers of the 1,3dienes 17-19 do not seem to have been recorded in the literature though some authors have claimed determination of $E$ and $Z$ isomers of 1,3-octadiene and 2-methyl-2,4-octadiene based on GLC ${ }^{14}$ without giving experimental conditions. Hauser et al. have observed the inability of some Carbowax columns to resolve 1,3-heptaand 1,3-nonadiene into $E$ and $Z$ isomers, ${ }^{15}$ and we have encountered similar difficulties though we used longer columns. To obtain a rough estimate of the stereoselectivity in the formation

Acta Chem. Scand. B 29 (1975) No. 5 
of 1,3-dienes, we reacted 1,3-heptadiene (prepared from 5 in diglyme), and 1,3-nonadiene with maleic anhydride, these reactions producing adducts in yields of 74 and $71 \%$, respectively (NMR). Predominant $E$ configuration of these dienes is thus indicated, ${ }^{13}$ and is further verified by the absorption of medium strength around $950 \mathrm{~cm}^{-1}$ in the IR spectra ${ }^{15,16}$ of all the mono-substituted 1,3-dienes.

4-Methyl-1,3-heptadiene (22) contained comparable amounts of $E$ and $Z$ isomers (55:45), irrespective of the starting material used ( 9 or 10).

The dienacetal 24 is obtained as a 1:1 mixture of $E$ and $Z$ isomers, whereas GLC on Carbowax of the dienol 25 was not conclusive (cf. Experimental Part).

The 1,4-disubstituted butadienes 20 and 21 exhibit remarkable differences in their content of stereoisomers. While the $E, E$ isomer of 2,4hexadiene $(20)$ is the major component $(E, E$ : $E, Z: Z, Z=61: 36: 3)$ the same isomer of 4,6-decadiene (21) only constitutes $35-45 \%$ ( $E, E: E, Z$ approximates $3: 5 ; Z, Z \sim 4 \%$ of the isomers), when both dienes were formed in diglyme. The poor GLC resolution did not permit more exact quantitation of the decadienes. These assign. ments of the stereoisomers are based on IR spectra of the isolated $(E, E)$-2,4-hexadiene, ${ }^{17}$ of a mixture of the $(E, Z)$ - and $(Z, Z)$-2,4-hexadienes, ${ }^{17}$ and of the partly purified $E, E$ and $E, Z$ isomers of 4,6-decadiene. The latter isomers had IR spectra closely resembling those of the corresponding 2,4-hexadienes. IR data on other pure isomers of 1,4-disubstituted butadienes also support the assignments of the 4,6. decadienes. ${ }^{18}$

\section{MECHANISM AND DISCUSSION}

During formation of a conjugated diene from an $\alpha$-allenic alcohol, one of the two doublebonds remains in the same position $\left(a \rightarrow a^{\prime}\right.$ in Fig. 1), while the other $(b)$ is shifted to become $c$ in the conjugated diene. It is possible and even likely that the two double-bond forming processes will exhibit different stereoselectivity. It can be seen in Fig. 1 that to give an $(E)-a^{\prime}$ doublebond, the hydride has to be delivered to the allenic system from the most hindered side, and therefore this process might be sensitive to the size of the group $R$. The present results (cf.

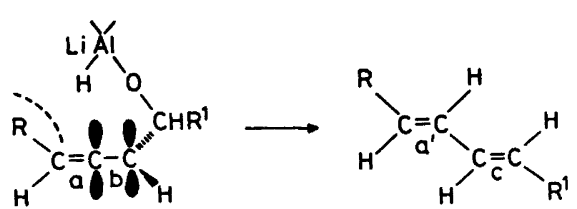

Fig. 1.

Stereochemistry) may corroborate these considerations, as 4,6-decadiene $\left(\mathrm{R}=\mathrm{R}^{1}=\mathrm{C}_{3} \mathrm{H}_{7}\right.$ in Fig. 1) contains more $E, Z$ isomer than 2,4hexadiene $\left(\mathrm{R}=\mathrm{R}^{1}=\mathrm{CH}_{3}\right)$. This hypothesis is even more likely, since the other process $b \rightarrow c$, which is an allylic rearrangement, can be expected to give more product of $E$ configuration the larger $R^{1}$ (Fig. 1) is. ${ }^{19}$

We found it of interest to study these processes in greater detail and therefore made the double-bonds of 2,4-hexadiene recognizable by labelling the starting acetylene 7 with deuterium at C-1 to give $7-d_{3}$. From $7-d_{3}$ the labelled 2,4-hexadiene 20-d $d_{3}$ was prepared in diglyme as for 20 and the isomers 30 and 31 were isolated together by preparative GLC. The deuterium content was $88 \%$ by NMR and $86.3 \%$ by MS. The 2,4-hexadiene system was chosen because all the isomers have been thoroughly investigated by $\mathrm{NMR},{ }^{20}$ showing the following methyl resonances relative to TMS (neat): $E, E, \delta 1.663$; the $E, Z$ isomer has the $E$ methyl at $\delta 1.710$ and the $Z$ methyl at $\delta 1.662$; $Z, Z, \delta 1.658$.<smiles>CC=CC=CC(=O)[O-]</smiles>

30<smiles></smiles>

31
The $E, Z$ isomer exhibits the two methyl signals separated by $0.05 \mathrm{ppm}$, and consequently the deuterium labelled $E, Z$ isomer can be analyzed for its content of $(E, Z)$ - and $(Z, E)$ 1,1,1-tri-deuterio-2,4-hexadiene (30 and 31 , respectively). The methyl region of this labelled isomer at $100 \mathrm{MHz}$ is shown in Fig. 2. When corrected for the presence of methyl signals from the $E, E$ and $Z, Z$ isomers (Fig. 2), both of which are found at $1.66 \mathrm{ppm}$, signals remain at 1.66 and $1.71 \mathrm{ppm}$ with the approximate ratio 


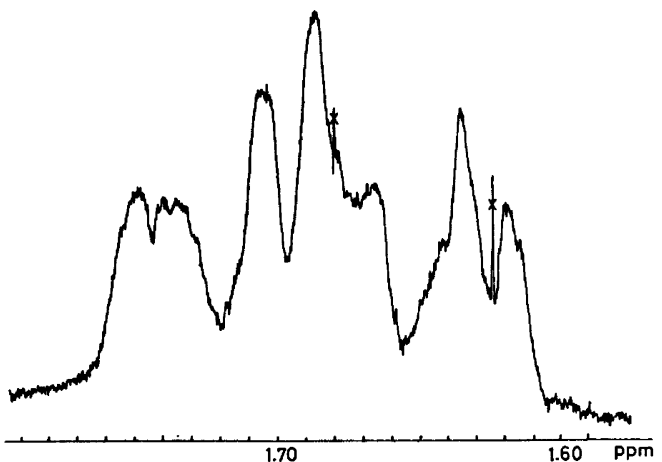

Fig. 2. $100 \mathrm{MHz}$ NMR spectrum of the methyl signals of the deuterium labelled $(E, Z)$ - and $(Z, E)$-2,4-hexadienes 30 and 31 containing 15 and $5 \%$ of the $Z, Z$ and $E, E$ isomers, respec. tively.

of areas 1:1.6, thus indicating the presence of 30 and 31 in the same ratio.

Assuming the chemical shifts of the $E$ and $Z$ methyl groups of $(E, Z)$-2,4-hexadiene to be correctly assigned by Albriktsen et $a l .{ }^{20}$ this experiment indicates that for the formation of 2,4-hexadiene there seems to be, very surprisingly, greater stereoselectivity for $E$ configuration in the rearrangement $a \rightarrow a^{\prime}$ than in the step $b \rightarrow c$ (Fig. 1). A major amount of the $E, E$ isomer is still formed and the total formation of $E$ configuration in the step $a \rightarrow a^{\prime}$ can be estimated to be around $84 \%$, while it is approximately $73 \%$ in the allylic rearrangement $b \rightarrow c$. The result is exactly reverse to what one should have expected from the foregoing reasoning (Fig. 1). The formation of $(E, Z)-4,6$-decadiene as the predominant isomer in the other experiment makes the situation still more complex since in this case the allylic rearrangement $b \rightarrow c$ would be expected to be still more $E$ stereoselective than in the formation of 2,4-hexadiene. However, it should be noted that the deuterium content of the 2,4-hexadiene, 20- $d_{3}$, is only $86.3 \%$ and the found difference between the stereoselectivities (84 and $73 \%$ ) is probably greater than the actual figure. Notwithstanding the ambiguous result with 2,4-hexadiene it still seems reasonable to assume that the bulk of the $Z$ double-bond of 4,6-decadiene is formed in the $a \rightarrow a^{\prime}$ mode though the situation might not be as straight-forward as pictured in Fig. 1 .
Finally, it is interesting to note that very small amounts of aluminium chloride in combination with the LAH reagent suffice to completely suppress the aforementioned formation of alkenynes. Other authors have also reported selective reactions with this reagent, notably the exclusive attack at C-3 on 3-alkyl substituted propargylic alcohols giving rise to organometallic intermediates ${ }^{21}$ or allenic hydrocarbons ${ }^{22}$ depending on the ratio of aluminium chloride:LAH. Without added aluminium chloride $\mathrm{LAH}$ attack occurs at $\mathrm{C}-2$ as well as C-3.21 Allylic alcohols can only undergo the above $\mathrm{S}_{\mathrm{N}} 2^{\prime} i$ reaction with $\mathrm{LAH}$ in exceptional cases. ${ }^{31,32}$ The presence of aluminium chloride is sometimes necessary ${ }^{32}$ but in other cases inhibitory..$^{31}$

\section{EXPERIMENTAL}

General. IR spectra were run on a PerkinElmer Infracord $157 \mathrm{G}$ apparatus using liquid films between $\mathrm{NaCl}$ discs. NMR spectra were obtained in $\mathrm{CDCl}_{3}$ with TMS as internal standard using a Perkin-Elmer R-12 B spectrometer operating at $60 \mathrm{MHz}$. These spectra were routinely recorded and are in full agreement with the proposed structures. The $100 \mathrm{MHz}$ spectrum was obtained with a Varian HA-100 D. Mass spectra were obtained at $70 \mathrm{eV}$ using an AEI MS-30 connected to a Pye 104 gas chromatograph. Correct mass spectra (M+ and fragmentation) were obtained for all conjugated dienes prepared in the present work with the exceptions of the dienes 19 and 24 , which were not run.

For preparative GLC $300 \times 0.96 \mathrm{~cm}$ and $600 \times 0.96 \mathrm{~cm}$ aluminium columns packed with $20 \%$ SE-30 and Carbowax $20 \mathrm{M}$, respectively, on Chromosorb W $(60-80$ mesh) were used. The Carbowax column was also used for determinations of stereoisomers.

All reactions involving $\mathrm{LiAlH}_{4}$ and Grignard reagents were performed under nitrogen atmosphere.

Propargylic ethers and acetals used in the subsequent preparations were 3-(tetrahydro-2pyranyloxy)propyne, ${ }^{23} 3$-(tetrahydro-2-pyranyloxy)-1-hexyne, ${ }^{2}$ 3-t-butoxy-1-hexyne, ${ }^{24}$ and 3 . methyl-3-(tetrahydro-2-pyranyloxy)-1-butyne..$^{25}$

2,2,2-Trideuterioacetaldehyde was prepared according to Baldwin, ${ }^{26}$ but only two exchanges in $\mathrm{D}_{2} \mathrm{O}$ were performed at $40^{\circ} \mathrm{C}$. Yield $50 \%$

General procedure for the preparation of 7 , $7-\mathrm{d}_{3}, 8,11$, and 12. To $0.5 \mathrm{~mol}$ of ethylmagnesium bromide in $150 \mathrm{ml}$ of THF was added the appropriate propargylic ether $(0.5 \mathrm{~mol})$ in $50 \mathrm{ml}$ of THF $(0.5 \mathrm{~h})$. Stirring was continued for $0.5 \mathrm{~h}$ at room temperature, when the

Acta Chem. Scand. B 29 (1975) No. 5 
appropriate keto compound dissolved in $25 \mathrm{ml}$ of THF, was added dropwise (1 h). After stirring for another $3 \mathrm{~h}$ at room temperature the reaction mixture was poured on to ice and ether, enough saturated $\mathrm{NH}_{4} \mathrm{Cl}$ solution was added to allow separation of the phases, and the water phase was extracted twice with ether. The organic phase was washed twice with a saturated $\mathrm{NH}_{4} \mathrm{Cl}$ solution, dried over $\mathrm{K}_{2} \mathrm{CO}_{3}-\mathrm{Na}_{2} \mathrm{SO}_{4}$ and distilled. 5-(Tetrahydro-2-pyranyloxy)-3-hexyn-2-ol (7). Yield $74 \%$. B.p. $102{ }^{\circ} \mathrm{C} / 0.3$ Torr. (Found: C 66.3; $\mathrm{H}$ 9.30. Calc. for $\mathrm{C}_{11} \mathrm{H}_{18} \mathrm{O}_{3}: \mathrm{C} 66.63 ; \mathrm{H}$ $9.15)$.

5-(Tetrahydro-2-pyranyloxy)-1,1,1-trideuterio3-hexyn-2-ol $\left(7-\mathrm{d}_{3}\right)$. Prepared on a $0.05 \mathrm{~mol}$ scale. Yield $67 \%$. B.p. $102{ }^{\circ} \mathrm{C} / 0.3$ Torr.

7-t-Butoxy-5-decyn-4-ol (8). Yield $66 \%$. B.p. $96{ }^{\circ} \mathrm{C} / 0.25$ Torr. (Found: $\mathrm{C} 74.1$; H 11.5. Calc. for $\mathrm{C}_{14} \mathrm{H}_{26} \mathrm{O}_{2}$ : C 74.29; $\mathrm{H}$ 11.58).

2-Methyl-5-(tetrahydro-2-pyranyloxy)-3-octyn2-ol (11). Yield $78 \%$. B.p. $108{ }^{\circ} \mathrm{C} / 0.4$ Torr. (Found: $\mathrm{C}$ 69.9; $\mathrm{H}$ 9.9. Calc. for $\mathrm{C}_{14} \mathrm{H}_{24} \mathrm{O}_{3}$ : C 69.96; H 10.07).

7-Methyl-7-(tetrahydro-2-pyranyloxy)-5-octyn4-ol (12). Yield $76 \%$. B.p. $109^{\circ} \mathrm{C} / 0.1$ Torr. (Found: C 69.9; $\mathrm{H}$ 9.8. Calc. for $\mathrm{C}_{14} \mathrm{H}_{24} \mathrm{O}_{3}$ : C 69.96 ; H 10.07).

The acetylenes 6 and 10 were prepared in analogy to similar compounds..$^{3,30}$ The intermediate acetylenic Thp-protected derivatives were methanolyzed without prior distillation.

4-Methoxy-2-nonyn-1-ol (6). Yield $74 \%$. B.p. $106^{\circ} \mathrm{C} / 0.6$ Torr. (Found: $\mathrm{C} 70.2 ; \mathrm{H}$ 10.3. Calc. for $\mathrm{C}_{10} \mathrm{H}_{18} \mathrm{O}_{2}$ : C 70.55; $\mathrm{H} \mathrm{10.66).}$

4-Methoxy-4-methyl-2-heptyn-1-ol (10). Yield $80 \%$. B.p. $66{ }^{\circ} \mathrm{C} / 0.5$ Torr. (Found: C 69.0; H 10.2. Calc. for $\mathrm{C}_{9} \mathrm{H}_{18} \mathrm{O}_{2}: \mathrm{C} 69.02 ; \mathrm{H} \mathrm{10.32).}$

Preparation of the conjugated dienes 18, 19, 21, 22,23 , and 24 from the acetylenes $4-6,8$ and 10-13. To a stirred, ice-cooled suspension of $\mathrm{LiAlH}_{4}(1.52 \mathrm{~g}, 30 \mathrm{mmol})$ in $20 \mathrm{ml}$ of THF a solution of the starting acetylene $(16 \mathrm{mmol}$ of Thp-oxy derivatives and $22 \mathrm{mmol}$ of alkoxy derivatives) in $10 \mathrm{ml}$ of THF was added dropwise. The mixture was refluxed for $4 \mathrm{~h}$, cooled and poured on to a little ice and $75 \mathrm{ml}$ of pentane. Saturated $\mathrm{NH}_{4} \mathrm{Cl}$ solution was added to facilitate the separation of the two phases. The water phase was extracted twice with pentane, and the combined organic phases were washed twice with saturated $\mathrm{NH}_{4} \mathrm{Cl}$ solution and twice with water, then dried over $\mathrm{Na}_{2} \mathrm{SO}_{4}$ while protected from air. The dienes were distilled or purified by preparative GLC after cautious evaporation of the pentane. Yields on distillation ranged from 40-70\%. However, it should be noted that GLC yields in most cases exceed $90 \%$ and still higher isolated yields can probably be achieved on a larger preparative scale.

4,6-Decadiene (21). Yield $55 \%$. B.p. $\sim 75^{\circ} \mathrm{C} /$ 20 Torr. The $E, E$ and $E, Z$ isomers were partly separated on a Carbowax $20 \mathrm{M}$ column at $115^{\circ} \mathrm{C}$. $(E, E)-4,6$-Decadiene (containing $\sim 25 \%$ of $E, Z$ isomer). IR: $985 \mathrm{~cm}^{-1}$ (strong) and 950 $\mathrm{cm}^{-1}$ (weak, from the $E, Z$ isomer). NMR: $\delta 6.50-5.20(\mathrm{~m}, 4 \mathrm{H}), 2.37-1.82(\mathrm{~m}, 4 \mathrm{H})$, 1.40 (sextet, $4 \mathrm{H}$ ) and $0.90(\mathrm{t}, 6 \mathrm{H})$. $(E, Z)-4,6$ Decadiene (containing $\sim 15 \%$ of $E, E$ isomer). IR: 982 and $950 \mathrm{~cm}^{-1}$ (both medium). NMR: $\delta 6.60-5.05(\mathrm{~m}, 4 \mathrm{H}), 2.37-1.83(\mathrm{~m}, 4 \mathrm{H})$, 1.40 (sextet, $4 \mathrm{H}$ ) and $0.90(t, 6 \mathrm{H}$ ).

6,6-Dimethoxy-4-methyl-1,3-hexadiene (24). Yield $53 \%$. B.p. $74^{\circ} \mathrm{C} / 15$ Torr. IR: $985 \mathrm{~cm}^{-1}$ (strong, $\mathrm{H}_{2} \mathrm{C}=$ ). NMR: $\delta$ 7.0-6.3 (m, $1 \mathrm{H}$ ), $5.95(d, 1 \mathrm{H}), 5.3-4.9(\mathrm{~m}, 2 \mathrm{H}), 4.50(\mathrm{t}, 1 \mathrm{H})$, $3.36(\mathrm{~s}, 6 \mathrm{H}), 2.50$ and 2.38 (two $\mathrm{d}, 2 \mathrm{H}$ ) and 1.83 $(\mathrm{s}, 3 \mathrm{H})$. (Found: C 68.8; H 10.2. Calc. for $\mathrm{C}_{9} \mathrm{H}_{16} \mathrm{O}_{2}$ : C 69.19; $\mathrm{H} \mathrm{10.33).}$

1,3-Heptadiene (18) from 5 in diglyme A 100 $\mathrm{ml}$ one-necked flask containing $30 \mathrm{ml}$ of diglyme was arranged so as to allow continuous distillation while a solution was added from the top. $\mathrm{LiAlH}_{4}(2.28 \mathrm{~g} ; 60 \mathrm{mmol})$ was added in several portions to the ice-cooled, magnetically stirred diglyme. A solution of $5^{24}(7.35 \mathrm{~g} ; 40 \mathrm{mmol})$ in $20 \mathrm{ml}$ of diglyme was added dropwise to the icecooled suspension, while the receiver was cooled to $-75^{\circ} \mathrm{C}$. The temperature of the reaction mixture was then slowly raised to $80^{\circ} \mathrm{C}$ using an oil-bath. After $2 \mathrm{~h}$ the oil-bath temperature was raised to $120^{\circ} \mathrm{C}$, when 1,3-heptadiene started to distill. The reaction system was connected to a water pump via a tube containing potassium hydroxide pellets, and the pressure was lowered to $\sim 50$ torr. $2.1 \mathrm{~g}$ of distilled material containing $10 \%$ of diglyme was obtained. 1,3-Heptadiene, >99\% pure by GLC except for the diglyme, was obtained in $47 \%$ yield.

2,4-Hexadiene (20) and 1,1,1-trideuterio-2,4hexadiene $\left(20-\mathrm{d}_{3}\right)$ were prepared in diglyme (30 mmol Thp-derivative and $50 \mathrm{mmol} \mathrm{LiAlH}_{4}$ ), but the reaction was allowed to proceed in a stoppered $250 \mathrm{ml}$ three-necked flask at $80^{\circ} \mathrm{C}$ for $3 \mathrm{~h}$. The reaction mixture was cooled, an efficient condensor was attached and the mix. ture was cooled to $-30^{\circ} \mathrm{C} .20 \mathrm{ml}$ of pentane was added, and then $10 \mathrm{ml}$ of water was added dropwise while magnetic stirring was maintained. The mixture was stirred for $0.5 \mathrm{~h}$ at $0{ }^{\circ} \mathrm{C}$ and then poured into a separatory funnel. It was diluted with saturated $\mathrm{NH}_{4} \mathrm{Cl}$, and the organic phase was separated and the water phase extracted twice with $5 \mathrm{ml}$ portions of pentane. The combined pentane solutions were washed several times with water and dried over $\mathrm{Na}_{2} \mathrm{SO}_{4}$. The $E, E$ and $E, Z$ isomers of the 2,4hexadienes were isolated by injecting $1 \mathrm{ml}$ portions of the pentane solutions on to a $6 \mathrm{~m}$ Carbowax column $\left(65^{\circ} \mathrm{C}\right)$ and collecting fractions at 18 and $20 \mathrm{~min}$. IR-spectra agreed with published data. ${ }^{17}$

3-Methyl-3,5-hexadien-1-ol (25). The acetal $13^{3}$ (2.3 $\left.\mathrm{g} ; 11.4 \mathrm{mmol}\right)$, was hydrolyzed in $30 \mathrm{ml}$ of dioxane:water (2:1) containing $75 \mathrm{mg}$ of $p$. toluenesulfonic acid $\left(70^{\circ} \mathrm{C}, 2 \mathrm{~h}\right)$. After cooling, $3 \mathrm{~g}$ of $\mathrm{KHCO}_{3}$ was added and then $\mathrm{Na}_{2} \mathrm{SO}_{4}$ to dry the mixture followed by $50 \mathrm{ml}$ of ether. After filtering the drying process was repeated 
once more. Evaporation of solvent in vacuo yielded the aldehyde 14 which was $\sim 93 \%$ pure by GLC. IR: 1720 (strong) and $1670 \mathrm{~cm}^{-1}$ (medium, H-bonding). NMR: $\delta 9.85$ (t, $1 \mathrm{H}$ ), 4.30 (s, $2 \mathrm{H}$ ), 3.45 (s, 3 H), 2.65 (d, $2 \mathrm{H}), 2.1$ (s, $1 \mathrm{H}$ ) and 1.50 (s, $3 \mathrm{H}$ ). It was not purified, but was allowed to react with $\mathrm{LiAlH}_{4}(0.70 \mathrm{~g}$; $18.5 \mathrm{mmol}$ ) in refluxing THF for $2 \mathrm{~h}$. Work-up and distillation yielded $100 \mathrm{mg}$ of the title compound (Fraction 1). A residue $(810 \mathrm{mg}$ ) after the distillation was shown by IR and NMR to be 4-methyl-2,3-hexadien-1,6-diol ( $c f$ Scheme in Table 1), better than $90 \%$ pure. This was once more allowed to react with $\mathrm{LiAlH}_{4}(0.57 \mathrm{~g} ; 15 \mathrm{mmol})$ for $6 \mathrm{~h}$. Work-up and distillation yielded $350 \mathrm{mg}$ of 25 . The total yield of 25 was $36 \%$. The first fraction was $\sim 95 \%$ pure by GLC on OV-25. IR: $900 \mathrm{~cm}^{-1}$ (strong, $\mathrm{H}_{2} \mathrm{C}=$ ). NMR $\delta 6.95-6.30(\mathrm{~m}, \mathrm{l} \mathrm{H}$ ), 5.95 (d of two $\mathrm{m}, 1 \mathrm{H}$ ), 5.30-4.90 (m, $2 \mathrm{H}$ ), 3.70 (t, $2 \mathrm{H}), 3.20$ (s, $1 \mathrm{H}$ ), 2.47 (q, $2 \mathrm{H}$; at 100 $\mathrm{MHz}$ shown to consist of two overlapping $t$ of almost equal intensity), and $1.80(\mathrm{~s}, 3 \mathrm{H})$. GLC $\left(6 \mathrm{~m}\right.$ Carbowax $20 \mathrm{M}$ at $210^{\circ} \mathrm{C}$ ) showed one main component (mol. wt 112, MS) at $19 \mathrm{~min}$ which constituted $80 \%$ of the whole mixture. Except for $5 \%$ of monoolefins (MS) there were two other components at 17 and $20.5 \mathrm{~min}$, representing 8 and $5 \%$, respectively. The second fraction consisted to approximately $25 \%$ of monoolefins.

Preparations of the conjugated dienes 15, 17, and 22 (from 9), $\mathrm{AlCl}_{3}$-procedure. Molar ratios and amounts of THF were the same as described above for the preparation of the other simple dienes. Instead of refluxing the reaction mixture it was kept stirring at $40{ }^{\circ} \mathrm{C}$ for $1 \mathrm{~h}$ to allow complete conversion of the starting acetylenes into $\alpha$-allenic alcohols. The mixture was then cooled to $0{ }^{\circ} \mathrm{C}$ and $\mathrm{AlCl}_{3}(1 \mathrm{~mol} \%$ of the $\mathrm{LiAlH}_{4}$ used) was added (in one portion for a 10-15 $\mathrm{mmol}$ preparation). The mixture was refluxed for $4 \mathrm{~h}$ and worked up as above.

Reactions of 1,3-heptadiene (18) and 1,3. nonadiene (19) with maleic anhydride. 1,3Heptadiene (375 mg; $3.34 \mathrm{mmol}$ ), obtained from 5 as described above, or 1,3-nonadiene (122 $\mathrm{mg} ; 0.97 \mathrm{mmol}$ ) was allowed to react with a $10 \%$ excess of maleic anhydride in $1-2 \mathrm{ml}$ of acetone in closed vials at $70^{\circ} \mathrm{C}$ for $10 \mathrm{~h}$. The solvent and unreacted dienes were removed in vacuo, and the residue was analyzed by NMR for yield. The amounts of olefinic protons in maleic anhydride and the adduct were compared. A $71 \%$ yield of adduct from 1,3-nonadiene and $74 \%$ from 1,3 -heptadiene was obtained.

Acknowledgement. I wish to thank Dr. Conny Bogentoft for most valuable discussions, and for running most of the mass spectra. I am indebted to Professor Bengt Danielsson for valuable discussions and to Dr. Curt Enzell, Swedish Tobacco Co., for GLC of some conjugated dienes (not described). This work has been supported financially by the Swedish Natural Science Research Council and with a grant from the Swedish Academy of Pharmaceutical Sciences.

\section{REFERENCES}

1. Claesson, A. and Bogentoft, C. Acta Chem. Scand. 26 (1972) 2540.

2. Cowie, J. S., Landor, P. D. and Landor, S. R. Chem. Commun. (1969) 541 and $J$. Chem. Soc. Perkin Trans. 1 (1973) 720.

3. Claesson, A., Olsson, L.-I. and Bogentoft, C. Acta Chem. Scand. 27 (1973) 2941.

4. Nayler, P. and Whiting, M. C. J. Chem. Soc. (1954) 4006.

5. Lutz, R. E., Bass, R. G. and Boykin, Jr., D. W., J. Org. Chem. 29 (1964) 3660; Kuhn, R. and Schulz, B. Chem. Ber. 98 (1965) 3218; Demole, E. and Enggist, P. Helv. Chim. Acta $5 \%$ (1974) 2087.

6. Bonnett, R., Mallams, A. K., Spark, A. A., Tee, J. L., Weedon, B. C. L. and McCormick, A. J. Chem. Soc. C (1969) 429; Cholnoky, L., Györgyfy, K., Rónai, A., Szabolcs, J., Tóth, Gy., Galasko, G., Mallams, A. K., Waight, E. S. and Weedon, B. L. C. Ibid. 1256.

7. Richey, Jr., H. G. and Szucs, S. S. Tetrahedron Lett. (1971) 3785.

8. Baudouy, R., Gore, J. and Roumestant, M.-L. Bull. Soc. Chim. Fr. (1973) 2506.

9. Taylor, D. R. Chem. Rev. 67 (1967) 317, see p. $349-350$.

10. Olsson, L.-I., Claesson, A. and Bogentoft, C. Acta Chem. Scand. 27 (1973) 1629.

11. Grob, C. A. and Spaar, R. Helv. Chim. Acta 53 (1970) 2119.

12. Brandsma, L. Preparative Acetylenic Chem. istry, Elsevier, Amsterdam 1971, p. 65.

13. von Brachel, H. and Bahr, U. In HoubenWeyl, Methoden der organischen Chemie, Georg Thieme Verlag, Stuttgart 1970, Band 5/lc, p. 1 .

14. Bogdanović, B. and Konstantinovic, S. Synthesis (1972) 481.

15. Hauser, C. F., Brooks, T. W., Miles, M. L., Raymond, M. A. and Butler, G. B. J. Org. Chem. 28 (1963) 372.

16. Greenwood, F. L. J. Org. Chem. 24 (1959) 1735.

17. Montgomery, L. K., Schueller, K. and Bartlett, P. D. J. Amer. Chem. Soc. 86 (1964) 622 .

18. Butenandt, A., Hecker, E., Hopp, M. and Koch, W. Justus Liebigs Ann. Chem. 658 (1962) 39.

19. Arora, A. S. and Ugi, I. K. In Houben-Weyl, Methoden der organischen Chemie, Georg Thieme Verlag, Stuttgart 1972, Band 5/1b, p. 905.

20. Albriktsen, P., Cuncliffe, A. V. and Harris, R. K. J. Magn. Resonance 2 (1970) 150. 
21. Corey, E. J., Katzenellenbogen, J. A. and Posner, G. H. J. Amer. Chem. Soc. 89 (1967) 4245.

22. Borden, W. T. and Corey, E. J. Tetrahedron Lett. (1969) 313; van Dijck, L. A., Lankwerden, B. J., Vermeer, J. G. C. M. and Weber, A. J. M. Rec. Trav. Chim. Pays-Bas 90 (1971) 801.

23. Henbest, H. B., Jones, E. R. H. and Walls, I. M. S. J. Chem. Soc. (1950) 3646.

24. Claesson, A. and Bogentoft, C. Synthesis (1973) 539 .

25. Robertson, D. N. J. Org. Chem. 25 (1960) 931.

26. Baldwin, J. E. and Pudussery, R. G. Chem. Commun. (1968) 408.

27. Kieffer, R. Bull. Soc. Chim. Fr. (1967) 3026.

28. List, G. R., Evans, C. D., Selke, E., Glass, C. A., Hoffmann, R. L. and McManis, G. E. Lipids 6 (1971) 635.

29. Claesson, A., Bogentoft, C., Danielsson, B. and Paalzow, L. Acta Pharm. Suec. 12 (1975). In press.

30. Olsson, L.-I., Claesson, A., and Bogentoft, C. Acta Chem. Scand. B 28 (1974) 765.

31. Borden, W. T. and Scott, M. Chem. Commun. (1971) 381.

32. Williams, H. J. Tetrahedron Lett. (1975) 1271 and references cited therein.

33. Baudouy, R. and Gore, J. Tetrahedron 31 (1975) 383.

Received December 11, 1974. 